\title{
Characterization of the proteasome from the extremely halophilic archaeon Haloarcula marismortui
}

\author{
B. FRANZETTI, ${ }^{1,2}$ G. SCHOEHN, ${ }^{3}$ D. GARCIA, ${ }^{1}$ R. W. H. RUIGROK ${ }^{3}$ and G. ZACCAI ${ }^{1}$ \\ ${ }^{1}$ Institut de Biologie Structurale, CNRS-CEA, 41 rue J. Horowitz, 38027 Grenoble cedex 1, France \\ 2 Author to whom correspondence should be addressed (franzetti@ibs.fr) \\ ${ }^{3}$ EMBL Grenoble Outstation, EMBL, PB156, 38042 Grenoble cedex 9, France
}

Received August 22, 2001; accepted October 22, 2001; published online November 15, 2001

\begin{abstract}
Summary A 20S proteasome, comprising two subunits $\alpha$ and $\beta$, was purified from the extreme halophilic archaeon Haloarcula marismortui, which grows only in saturated salt conditions. The three-dimensional reconstruction of the H. marismortui proteasome (Hm proteasome), obtained from negatively stained electron micrographs, is virtually identical to the structure of a thermophilic proteasome filtered to the same resolution. The stability of the $\mathrm{Hm}$ proteasome was found to be less salt-dependent than that of other halophilic enzymes previously described. The proteolytic activity of the $\mathrm{Hm}$ proteasome was investigated using the malate dehydrogenase from H. marismortui (HmMalDH) as a model substrate. The HmMalDH denatures when the salt concentration is decreased below $2 \mathrm{M}$. Under these conditions, the proteasome efficiently cleaves HmMalDH during its denaturation process, but the fully denatured $\mathrm{HmMalDH}$ is poorly degraded. These in vitro experiments show that, at low salt concentrations, the $20 \mathrm{~S}$ proteasome from halophilic archaea eliminates a misfolded protein.
\end{abstract}

Keywords: archaeabacteria, halophiles, stress.

\section{Introduction}

Extreme halophilic microorganisms thrive in ecological niches such as the Great Salt Lakes or the Dead Sea, where the salt concentration is close to saturation. Halophilic archaebacteria accumulate $\mathrm{KCl}$ to multi-molar concentrations (over $3 \mathrm{M}$ ) in their cytosol to compensate for the external osmotic pressure (Ginzburg et al. 1970). Most halophilic proteins denature when the salt concentration decreases, whereas high concentrations of salt normally alter non-halophilic protein stability and solubility (Timasheff 1993, Madern et al. 2000). Therefore, to remain stable and soluble in saturated saline conditions, halophilic proteins must have developed adaptative mechanisms. The main characteristic of soluble halophilic enzymes is their high content of acidic residues (Eisenberg et al. 1992). High-resolution structures of three halophilic proteins show that the acidic residues are localized in patches on the protein surface (Dym et al. 1995, Frolow et al. 1996, Pieper et al. 1998). An extensive study of malate dehydrogenase from Haloarcula marismortui has led to the conclusion that hydrated salt ions are associated with acidic residues situated on the protein surface in such a way that the salt concentration of the solvation layer is higher than that of the bulk solvent (Bonnete et al. 1994, Madern et al. 1995, Ebel et al. 1999). It was suggested that this characteristic allows halophilic proteins to remain stable and soluble in high salt concentrations (Zaccai et al. 1989). This structural adaptation to extreme salt conditions implies that variation in salt concentration in the environment represents a severe stress for extreme halophilic organisms. Hence, in the crowded cytosolic environment, misfolded proteins generated by low-salt stress may aggregate and cause cell death (Ellis and Hartl 1999).

It has been proposed that, in archaea, the $20 \mathrm{~S}$ proteasome, which constitutes the core of the central protease in the protein degradation pathway (Dahlmann et al. 1989, Baumeister et al. 1998), could be responsible for the nonspecific elimination of abnormal proteins generated by various stresses, in addition to its role in controlling the rate of protein turnover (MaupinFurlow et al. 2000, Sherman and Goldberg 2001). The structure of the 20S proteasome from the archaeon Thermoplasma acidophilum has been extensively studied (Zwickl et al. 1992, Lowe et al. 1995, Lupas et al. 1997) and found to represent a simplified version of those in eukaryotic systems. In archaea, the $20 \mathrm{~S}$ proteasome consists of only two types of subunits ( $\alpha$ and $\beta$ ) arranged in four stacked rings of seven subunits each, whereas the eukaryotic proteasome contains seven distinct subunits (Coux et al. 1996, Baumeister et al. 1998). The two outer rings of the $20 \mathrm{~S}$ proteasome are composed of $\alpha$-type subunits, whereas the two inner rings are composed of $\beta$-type subunits, which bear the proteolytic active sites (Seemuller et al. 1995). The proteasome eliminates the majority of proteins in a processive mechanism generating small peptides (Akopian et al. 1997, Kisselev et al. 1999). However, the initial process that leads to the degradation of proteins in a cell is still unclear. The process is energy dependent and consists of recognizing the protein to be degraded and then rendering the substrate accessible to the compartmentalized active sites of the proteasome (Schmidt et al. 1999). The energy-dependent recognition step 
is believed to control the destruction of the proper proteins. In eukaryotes, the proteins to be degraded are first tagged by ubiquitin (Hershko and Ciechanover 1998). Such ubiquitin targeting systems have not been identified in prokaryotes, and little is known about how native substrate proteins are recognized for degradation in archaea. In prokaryotes and eukaryotes, the native protein targeted for degradation by self-compartmentalizing proteases is recognized by other regulatory complexes that can also act as molecular chaperones (Horwich et al. 1999). In eukaryotes, the 19S cap is a multi-subunit complex that associates with the $20 \mathrm{~S}$ proteasome to form the energy-dependent 26S proteasome (Coux et al. 1996). The base domain of the $19 \mathrm{~S}$ cap comprises six subunits that form a ring-shaped complex that possesses ATPase activity and belongs to the AAA (ATP:ADP antiporter) family (Russell et al. 1996, Patel and Latterich 1998). In archaea, a homolog of this $26 \mathrm{~S}$ eukaryotic proteasome activating complex, called PAN (proteasome activating nucleotidase), has been characterized (Zwickl et al. 1999, Wilson et al. 2000). These complexes are believed to recognize exposed hydrophobic surfaces of improperly folded proteins and display unfoldase (reverse chaperone) activity that triggers protein degradation (Glickman et al. 1998, Wickner et al. 1999, Benaroudj and Goldberg 2000).

Because of their specific adaptation to extreme conditions (e.g., temperature, salt, pressure and $\mathrm{pH}$ ), archaeal cells represent appropriate model systems to study the environmental stress response. Little is known about the biological significance of the 20S archaeal proteasome in the stress response and substrate proteins have not been identified. It is likely that ATP-dependent regulatory complexes, such as PAN, are indispensable for the elimination of abnormal proteins (Sherman and Goldberg 2001). However, in microorganisms, the $20 \mathrm{~S}$ proteasome can function autonomously in the efficient degradation of misfolded proteins in the cell during extreme environmental stress. The objective of this work was to study in vitro the stability and proteolytic activity of the proteasome in H. marismortui.

A proteasome from Haloferax volcanii was previously characterized by Wilson et al. (1999). Compared with H. marismortui, $H$. volcanii is a moderate halophile that requires a lag period and synthesis of specific, high-salt-related proteins to adapt to hypersaline conditions (Mullakhanbhai and Larsen 1975, Mojica et al. 1997). The function of the $H$. volcanii proteasome was found to be salt dependent. However, the method used to assess the in vitro activity did not discriminate between the salt concentration needed for enzymatic activity and that needed for stability. Here, we studied independently the catalytic activity and the stability of the proteasome from H. marismortui (Hm proteasome). Malate dehydrogenase from H. marismortui (HmMalDH) was found to be a good substrate in protease assays and we studied the proteasome activity in low salt concentration. We also obtained the three-dimensional (3-D) structure for the Hm proteasome by image reconstruction from negatively stained electron micrographs and compared it with the X-ray crystal structure of its homolog from T. acidophilum. Our results provide new insight into the functioning of the $20 \mathrm{~S}$ archaeal proteasome.

\section{Materials and methods}

\section{Strains, media and culture conditions}

Haloarcula marismortui cells were kindly provided by A. Oren (University of Jerusalem). Cells were cultivated in 2-1 flasks at $37{ }^{\circ} \mathrm{C}$ with gentle agitation in a growth medium containing $3.5 \mathrm{M} \mathrm{NaCl}$ (Mevarech et al. 1977). Cells were harvested at $\mathrm{OD}_{660}=2$ by centrifugation for $1 \mathrm{~h}$ at $12,000 \mathrm{~g}$ and stored at $-80{ }^{\circ} \mathrm{C}$ until use.

\section{Purification of the H. marismortui proteasome}

Cell pellets (usually corresponding to 301 of culture) were thawed and suspended in one volume of Buffer A $(50 \mathrm{mM}$ Tris- $\mathrm{HCl}, 2.2 \mathrm{M}\left(\mathrm{NH}_{4}\right)_{2} \mathrm{SO}_{4}, 40 \mathrm{mM} \mathrm{MgAc}_{2}, \mathrm{pH}$ 7.6) containing $20 \mathrm{mg}$ of grade II DNaseI (Boehringer Mannheim). After $30 \mathrm{~min}$ of agitation at room temperature, aliquots of the cell lysate were homogenized by ultrasonication $(6 \times 10 \mathrm{~s})$. The cell extract was centrifuged for $60 \mathrm{~min}$ at $30,000 \mathrm{~g}$. The supernatant was centrifuged for $2 \mathrm{~h}$ at 160,000 $\mathrm{g}$. After a 48-h dialysis against Buffer A at $4{ }^{\circ} \mathrm{C}$, the $\mathrm{S} 160$ supernatant was then mixed batchwise with $400 \mathrm{ml}$ of Sepharose 4B (Pharmacia) equilibrated in Buffer A. Note that Sepharose $4 \mathrm{~B}$ is used as a hydrophobic interaction column in halophilic protein purification processes. After a $2-\mathrm{h}$ incubation at room temperature, the gel was packed in a $5.5 \times 30 \mathrm{~cm}$ column and protein was eluted based on hydrophobicity with a linear ammonium sulfate $\left(\left(\mathrm{NH}_{4}\right)_{2} \mathrm{SO}_{4}\right)$ gradient $(2.2-0.4 \mathrm{M}$ in $950 \mathrm{ml}$ of Buffer A). Haloarcula marismortui cells were found to contain a strong endogeneous peptidase activity in the first stages of the purification that interfered with the detection of the proteasome chymotrypsin-like activity when using a typical fluorogenic substrate. Moreover, the protein fractions contained a substance that fluoresced when excited at $360 \mathrm{~nm}$. We therefore used electron microscopy to look for rod-shaped particles that resembled proteasomes in the protein extracts. Fractions containing both rod-shaped particles and chymotrypsin-like activity, obtained at approximately $0.6 \mathrm{M}\left(\mathrm{NH}_{4}\right)_{2} \mathrm{SO}_{4}$, were pooled and solid ammonium sulfate was added to a concentration of 1.9 M. The sample was applied to a DE52 cellulose column $(2.6 \times 25 \mathrm{~cm})$ equilibrated in $50 \mathrm{mM}$ Tris, $2 \mathrm{M}\left(\mathrm{NH}_{4}\right)_{2} \mathrm{SO}_{4}, \mathrm{pH}$ 7.6. Proteins were eluted with a decreasing $\left(\mathrm{NH}_{4}\right)_{2} \mathrm{SO}_{4}$ gradient (1.9-0.5 M) and an increasing $\mathrm{NaCl}$ gradient $(0-2 \mathrm{M})$ over $500 \mathrm{ml}$. The active fractions, obtained at $0.8 \mathrm{M} \mathrm{NaCl}$ and $1.2 \mathrm{M}$ $\left(\mathrm{NH}_{4}\right)_{2} \mathrm{SO}_{4}$, were pooled and dialyzed against $20 \mathrm{mM}$ sodium phosphate buffer containing $4 \mathrm{M} \mathrm{NaCl}$. The protein sample was applied to a column $(1.5 \times 10 \mathrm{~cm})$ of hydroxyapatite (BioRad) pre-equilibrated with dialysis buffer. The column was developed at $18 \mathrm{ml} \mathrm{h}^{-1}$ with a 200-ml linear phosphate gradient from 20 to $300 \mathrm{mM}$ phosphate in $4 \mathrm{M} \mathrm{NaCl}$. The fractions containing the proteasome subunits were dialyzed against $2 \mathrm{M} \mathrm{KCl}$ in $20 \mathrm{mM}$ Tris- $\mathrm{HCl}, \mathrm{pH}$ 7.6. The sample was applied to a G4000 (TosoHaas, Montgomeryville, PA) gel filtration column mounted on an HPLC system. The elution 
buffer was $2 \mathrm{M} \mathrm{KCl}$ in $20 \mathrm{mM}$ Tris- $\mathrm{HCl}, \mathrm{pH} 7.6$ at $0.9 \mathrm{ml}$ $\mathrm{min}^{-1}$. Protein concentration was determined by the method of Bradford with bovine serum albumin (BSA) as the standard (Bradford 1976). The SDS-polyacrylamide gel electrophoresis (12\%) was performed according to Laemmli (1970).

\section{Peptidase assays}

Chymotrypsin-like activity was assayed fluorimetrically following the release of 7-amino-4-methylcoumarin (AMC) from the synthetic peptide succinyl-Leu-Leu-Val-Tyr-AMC (Bachem, Bubendorf, Switzerland). The assay mixture was prepared by dissolving the fluorogenic peptide $(10 \mathrm{mM}$ in DMSO) at $100 \mathrm{nM}$ final concentration in $20 \mathrm{mM}$ Tris- $\mathrm{HCl}$, $\mathrm{pH}$ 7.6, containing various $\mathrm{KCl}$ concentrations. Assays were initiated by addition of $2 \mu \mathrm{g}$ of enzyme to $1 \mathrm{ml}$ of preheated assay mixture. The hydrolysis of substrate was monitored in a continuous rate assay at different temperatures and in different salt conditions in a thermostatically controlled fluorimeter. Linear rates of increasing fluorescence intensity were recorded for up to $10 \mathrm{~min}$ at an excitation wavelength of $370 \mathrm{~nm}$ and emission of $460 \mathrm{~nm}$. The fluorimeter was calibrated with AMC solutions prepared in the assay buffer. Specific activity is expressed as nmol of AMC released per min per mg of protein.

\section{Stability}

For stability measurements, $2.5 \mu \mathrm{g}$ of purified proteasome was incubated for $24 \mathrm{~h}$ at $40^{\circ} \mathrm{C}$ in $500 \mu \mathrm{l}$ of assay buffer containing $20 \mathrm{mM}$ to $2 \mathrm{M} \mathrm{KCl}$. The residual activity was measured at $40{ }^{\circ} \mathrm{C}$ after the addition of one volume of preheated substrate peptide solution (final concentration of $100 \mathrm{mM}$ ) containing the appropriate amount of $\mathrm{KCl}$ to attain a final concentration of 0.5 M. Halophilic malate dehydrogenase stability was estimated in parallel experiments and the residual activity was measured as described by Cendrin et al. (1993).

\section{Degradation of halophilic malate dehydrogenase}

Recombinant halophilic HmMalDH was over-expressed in Escherichia coli and purified in an active state as described by Cendrin et al. (1993). The pure protein was stored at $4{ }^{\circ} \mathrm{C}$ in $3 \mathrm{M} \mathrm{KCl}, 50 \mathrm{mM}$ Tris- $\mathrm{HCl}, \mathrm{pH}$ 8. For the protease assay, the enzyme was diluted 20 -fold in $20 \mathrm{mM}$ Tris- $\mathrm{HCl}$, $\mathrm{pH} 7.6$ containing either 3 or $0.4 \mathrm{M} \mathrm{KCl}$, to give a final enzyme concentration of $0.05 \mathrm{mg} \mathrm{ml}^{-1}$. Complete enzyme inactivation was reached in the $0.4 \mathrm{M} \mathrm{KCl}$ denaturing buffer after a 30-min incubation at $40{ }^{\circ} \mathrm{C}$ as monitored by the enzymatic assay described by Zaccai et al. (1989). Native or denatured malate dehydrogenase $(0.1 \mu \mathrm{g})$ was mixed with $2.8 \mu \mathrm{g}$ of proteasome in $100 \mu \mathrm{l}$ of $20 \mathrm{mM}$ Tris-HCl buffer, $\mathrm{pH} 7.6$ containing different $\mathrm{KCl}$ concentrations (from 0.4 to $2 \mathrm{M}$ ). We used low-adhesion micro-tubes that were previously pre-quenched with BSA to avoid nonspecific retention of denatured malate dehydrogenase. The mixtures were incubated for $1 \mathrm{~h}$ at $40{ }^{\circ} \mathrm{C}$. Reactions were stopped by addition of $200 \mu \mathrm{l}$ of $20 \%$ trichloroacetic acid with $10 \mu \mathrm{g}$ of tRNA as a carrier. Samples were centrifuged (30 min at 12,000 $\mathrm{g}$ ) and pellets were washed with cold acetone, dried and resuspended in $20 \mu \mathrm{l}$ of $20 \mathrm{mM}$ Tris-base. Proteins were resolved by SDS-PAGE using $15 \%$ polyacrylamide and blotted on a Hybond-P nitrocellulose membrane (Amersham) according to the manufacturer's protocol. The HmMalDH was immunodetected with rabbit polyclonal antibodies raised against the protein using the ECL detection kit from Amersham-Pharmacia.

\section{The $90^{\circ}$ scattering experiments}

To follow HmMalDH aggregation, we used a spectrofluorimeter (SLM/Aminco, Champaign, IL) with an excitation and emission light of $400 \mathrm{~nm}$. In the cuvette, we diluted either the denatured (in $0.4 \mathrm{M} \mathrm{KCl}$ ) or the native (in $3 \mathrm{M} \mathrm{KCl}$ ) $\mathrm{HmMalDH}$ to give a final protein concentration of $20 \mu \mathrm{g} \mathrm{ml}^{-1}$ and for $2 \mathrm{~h}$ monitored light at $400 \mathrm{~nm}$ that was scattered at $90^{\circ}$.

\section{Electron microscopy}

We used negative staining rather than cryo-electron microscopy because of the high concentration of salt in the samples. Sample $\left(0.1 \mathrm{mg} \mathrm{ml}^{-1}\right)$ was absorbed to the clean side of a carbon film on mica, stained with $2 \%$ (w/v) ammonium molybdate, and transferred to a 400-mesh copper grid. Specimens were observed with a JEOL 1200 EX II microscope at $100 \mathrm{kV}$. Images were obtained under low dose conditions $\left(<100 \mathrm{e}^{-}\right.$per $\mathrm{nm}^{2}$ ) at a nominal magnification of $40,000 \times$ with a defocus chosen so that the first zero of the contrast transfer function (CTF) was beyond $2.0 \mathrm{~nm}^{-1}$. The images were recorded on KODAK SO163 film and developed in 1/3 strength KODAK D19 developer for $9 \mathrm{~min}$ at room temperature.

\section{Image processing and 3-D reconstruction}

Image quality was checked on an optical bench and 10 selected images were digitized on an Optronics microdensitometer, with a step size of $25 \mu \mathrm{m}$ corresponding to a pixel size of 0.625 $\mathrm{nm}$ on the specimen. Particle selection was performed with the MRC program, Ximdisp (Crowther et al. 1996). A total of 1000 side views and 150 top views of the particles were selected, band pass filtered between 25-2 nm without CTF correction, and normalized to the same mean and standard deviation with SPIDER (a system for processing image data in electron microscopy and related fields; Wadsworth Center, NY). Multivariate statistical analysis in SPIDER was used in the initial analysis to determine the symmetry of the top views. This preliminary analysis gave unambiguously 7 -fold symmetry for the macromolecule (data not shown). We used only the side views because they give full 3-D information when they are combined with 7-fold symmetry. The image analysis was performed with only the asymmetric unit of the macromolecule $\left(1 / 7\right.$ of $\left.360^{\circ}\right)$ (Roseman et al. 1996). We generated a preliminary 3-D model by back projection, applying 7-fold symmetry to a single centered side view. This model was reprojected in side views and low tilted $\left(10\right.$ and $\left.20^{\circ}\right)$ side views with the same azimuthal distribution $\left(5^{\circ}\right)$. All the images were aligned against the projections of this model. The images that matched with one angular class were summed and the mean and variance were calculated. The average images of the side 
views with a good variance map were used to generate a new model by iterative back projection. This reconstruction was used as a new model and five iterative cycles were performed with the same azimuthal distribution. Because the model converged, we increased the azimuthal distribution to 52 (one projection every degree). After 20 more cycles the model and class distribution were stable and the refinement was complete. Ten to 15 images matched with each class. The reconstruction was made by back projection based on the 52 class means. The threshold used (see Figure 4d) was chosen to include the correct molecular weight. The resolution was determined to be $2.1 \mathrm{~nm}$ by Fourier shell correlation (50\% value).

\section{Results}

\section{Purification of the H. marismortui 20 S proteasome}

We identified two bands on SDS-PAGE, with $M_{\mathrm{r}}$ of 32 and $25 \mathrm{kDa}$, that co-purified with proteasome-containing fractions. These proteins were purified to homogeneity by a protocol in which all steps were performed in high salt concentration to maintain halophilic protein stability. An SDS-PAGE gel is shown in Figure 1. In the first steps the "salting out" effect of the high ammonium sulfate concentration stabilized the proteins, which were loaded on a Sepharose 4B column used as a hydrophobic interaction column. Bound proteins were eluted with a negative ammonium sulfate gradient. Fractions containing the proteasome were pooled and the ammonium sulfate concentration was increased to allow binding of the proteins on an anion-exchange column. A negative ammonium sulfate gradient combined with a positive sodium chloride gradient was used for protein separation. This step had a poor yield but was necessary to obtain good recovery from the subsequent hydroxyapatite affinity chromatography step. The 20 S proteasome was finally separated from other contaminat-

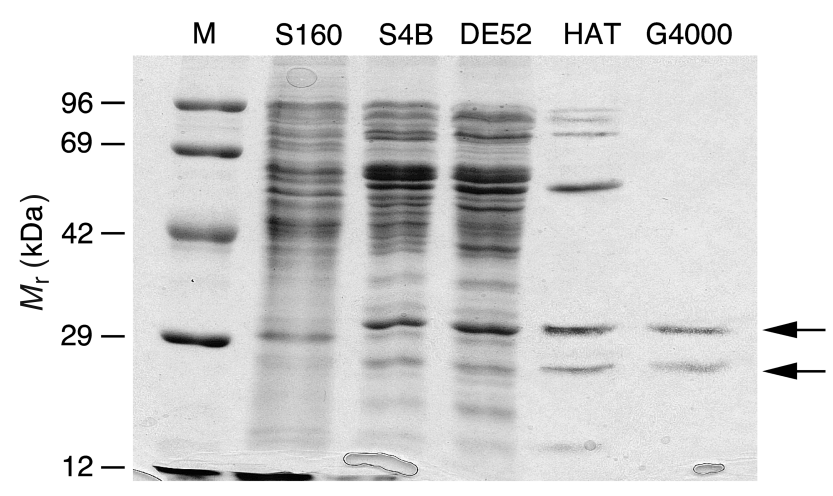

Figure 1. SDS-polyacrylamide gel electrophoresis of fractions from different purification steps of the proteasome from $H$. marismortui. Abbreviations: M, molecular weight markers; S160, H. marismortui extract after ultracentrifugation; S4B, proteasome pooled after Sepharose 4B chromatography; DE52, proteasome pooled after DEAESepharose chromatography; HAT proteasome pooled after hydroxyapatite chromatography; G4000, pure proteasome pooled after gel filtration on a G4000 HPLC column (TosoHaas). The arrows indicate the $\alpha$ and $\beta$ subunits of the proteasome. ing high molecular weight complexes by gel filtration in hyper-saline conditions using a G4000 column mounted on an HPLC system. After calibration of the column with non-halophilic proteins, $M_{\mathrm{r}}$ of the native particle was estimated to be about $700 \mathrm{kDa}$. Electron microscopy analysis allowed unambiguous identification of the complex as the 20S proteasome (see below). The purified particle consisted of two subunits of 32 and $25 \mathrm{kDa}$ corresponding to the $\alpha$ and $\beta$ subunits, respectively.

\section{Peptidase activity and stability of the H. marismortui proteasome in different salt concentrations}

Archaeal proteasomes exhibit high activity with chymotryptic substrates. The fluorogenic peptide Suc-Leu-Leu-Val-TyrAMC was chosen to test for endopeptidase activity. Potassium chloride was chosen as the standard salt instead of $\mathrm{NaCl}$ because $\mathrm{KCl}$ accumulates in all living cells. We found that, like the $H$. volcanii proteasome, the optimum temperature for $\mathrm{Hm}$ proteasome endopeptidase activity was $60{ }^{\circ} \mathrm{C}$ when measured in an assay buffer containing $2 \mathrm{M} \mathrm{KCl}$ (data not shown). High salt adaptation often leads to an increase in protein stability over a wide range of environmental conditions (Zaccai et al. 1989, Madern et al. 2000). This adaptation could be the result of an increased number of salt bridge clusters, as has been observed in HmMalDH (Richard et al. 2000). At $40{ }^{\circ} \mathrm{C}$, the purified proteasome complex had a maximum specific activity of

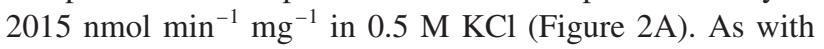
most of the halophilic enzymes studied thus far, maximum proteasome activity occurred at a salt concentration where the substrate protein was unstable (see below) (Mevarech et al. 1977). The peptidase activity of the halophilic proteasome showed a rapid drop in activity below $0.5 \mathrm{M}$ salt. This is a common feature of halophilic enzymes and is believed to reflect denaturation of the enzyme, rather than a salt requirement for catalytic activity (Zaccai et al. 1989). The activity was three times lower in hypersaline salt solution, which is similar to the halophilic enzymes of the H. marismortui cytosol (Ginzburg et al. 1970). A decrease in enzymatic activity in high salt concentration has also been observed in other halophilic proteins (reviewed by Madern et al. 2000).

The $\mathrm{Hm}$ proteasome requires salt concentrations above $0.5 \mathrm{M} \mathrm{KCl}$ for stability (Figure 2B). This finding contrasts with most halophilic enzymes, including HmMalDH, which are unstable after long periods in salt concentrations below 2.5 M (Figure 2B). We conclude that the Hm proteasome displays high stability under salt conditions where halophilic proteins denature.

\section{Degradation of halophilic malate dehydrogenase by $\mathrm{Hm}$ proteasome activity}

In vitro, the common substrates used to assay proteolytic activity of the $20 \mathrm{~S}$ proteasomes consist of small proteins like casein or proteins that have been denaturated by extreme thermal or oxidative stress (Rivett et al. 1994). Because Hm proteasome is stable in salt conditions whereas HmMalDH denatures, it was possible to study the proteolytic activity of the $\mathrm{Hm}$ 

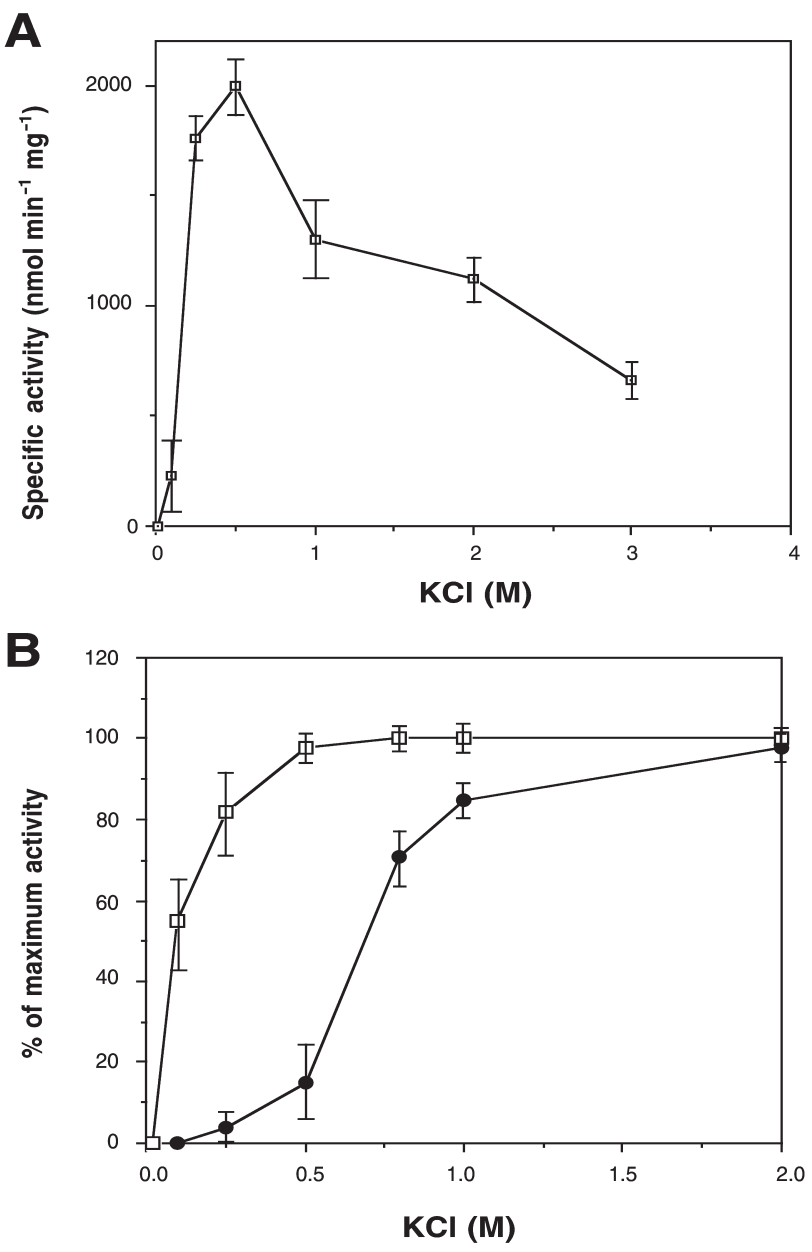

Figure 2. Salt-dependent activity and stability of the H. marismortui proteasome. (A) Halophilic proteasome activity. Peptidase activity was assayed by the hydrolysis of the synthetic peptide Suc-Leu-LuVal-Tyr-AMC. Continuous rate assays were performed in a thermostatically controlled fluorimeter and the initial reaction rate was measured at $40^{\circ} \mathrm{C}$ in different $\mathrm{KCl}$ concentrations. (B) Effect of salt on the stability of the $H$. marismortui proteasome. Purified $\mathrm{Hm}$ proteasome $(\square)$ or $\mathrm{Hm}$ MalDH were diluted in various salt concentrations and incubated for $24 \mathrm{~h}(\mathbf{O})$. The residual peptidase activity was measured as in (A) in a reaction mixture containing $0.5 \mathrm{M} \mathrm{KCl}$. The residual malate dehydrogenase activity was measured as described in Madern et al. (1995). Standard error bars are derived from three or four measurements.

20S proteasome during ongoing denaturation of the substrate protein. Peptidase activity assays were performed to ensure that the proteasome remained stable during incubation. We found that $0.4 \mathrm{M} \mathrm{KCl}$ is the limiting salt concentration below which the Hm proteasome begins to deactivate during incubation at $40{ }^{\circ} \mathrm{C}$. Because we aimed to assess the proteolytic activity in different salt concentrations on folded and unfolded substrates, we first studied the denaturation rates of HmMalDH by fluorescence measurements and activity tests. The HmMalDH deactivated completely during a 1-h incubation in salt concentrations below $2 \mathrm{M}$. We verified that HmMalDH denatured by low salt concentration remained un- folded even when returned to high salt concentrations such as $2 \mathrm{M} \mathrm{KCl}$. No aggregation signal was observed during light scattering measurements indicating that, under our experimental conditions, HmMalDH denatured by low salt concentration is still soluble and therefore susceptible to proteolytic attack (data not shown). The same conclusion was drawn from previous neutron scattering, laser scattering and analytical ultracentrifugation experiments (Pundak et al. 1981, Zaccai et al. 1986).

The native or salt-denatured HmMalDH was incubated with proteasome in the assay mixture for $1 \mathrm{~h}$. The data presented in Figure 3 demonstrate proteolysis of HmMalDH by the halophilic proteasome. The decrease in the specific HmMalDH signal on Western blots was used to assay for protease activity. Significant protease activity occurred in the presence of $0.4 \mathrm{M}$ $\mathrm{KCl}$ when denatured $\mathrm{HmMalDH}$ was used as the substrate. Proteolytic activity was negligible at salt concentrations above $0.6 \mathrm{M}$ (even over long periods). However, when native HmMalDH was used as a substrate (i.e., when the denaturation process occurred during the incubation with the proteasome) we found that the protein was degraded in all salt concentrations in which it destabilized (from 0.4 to $1.5 \mathrm{M} \mathrm{KCl}$ ) (Figure 3 ). Note that the absence of HmMalDH degradation in salt concentrations above $2 \mathrm{M}$ cannot be attributed to precipitation or denaturation caused by high salt concentration because studies show that $\mathrm{HmMalDH}$ is maximally soluble at $\mathrm{KCl}$ concentrations above $3 \mathrm{M}$ (Ebel et al. 1999). The rate of cleavage was proportional to the rate of HmMalDH denaturation as estimated by deactivation kinetics. Therefore, we conclude that HmMalDH undergoing denaturation is a better substrate for the $\mathrm{Hm}$ proteasome than the fully denatured polypeptide chain.

\section{Three-dimensional structure of the halophilic proteasome}

To determine possible differences between the structure of the halophilic proteasome and that of the thermophilic proteasome, we studied its 3-D structure by electron microscopy. Cryo-electron microscopy of proteins at high salt concentration does not provide reasonable contrast between the proteins and the aqueous medium. Therefore, we studied the proteasome with negative staining. Several stains were tested, and $1 \%$ ammonium molybdate gave the best results. The medium resolution results that were obtained from the 3 -D reconstruction suggest that there was little or no particle flattening during the staining and air-drying procedure. The variance maps of the class mean did not show size differences. The field in Figure 4 shows end and side views. Often the particles in side view are attached at one or both ends to particles in end view, sometimes leading to the formation of chains. This tendency of the proteasome to interact end to side was not a problem for the reconstruction because the end-orientated proteasome never occupied exactly the same position on the side-orientated proteasome. During the alignment, all end views were averaged and we did not observe enhanced image density on completion of proteasome reconstruction (at the threshold image density giving the right volume according to the molecular 


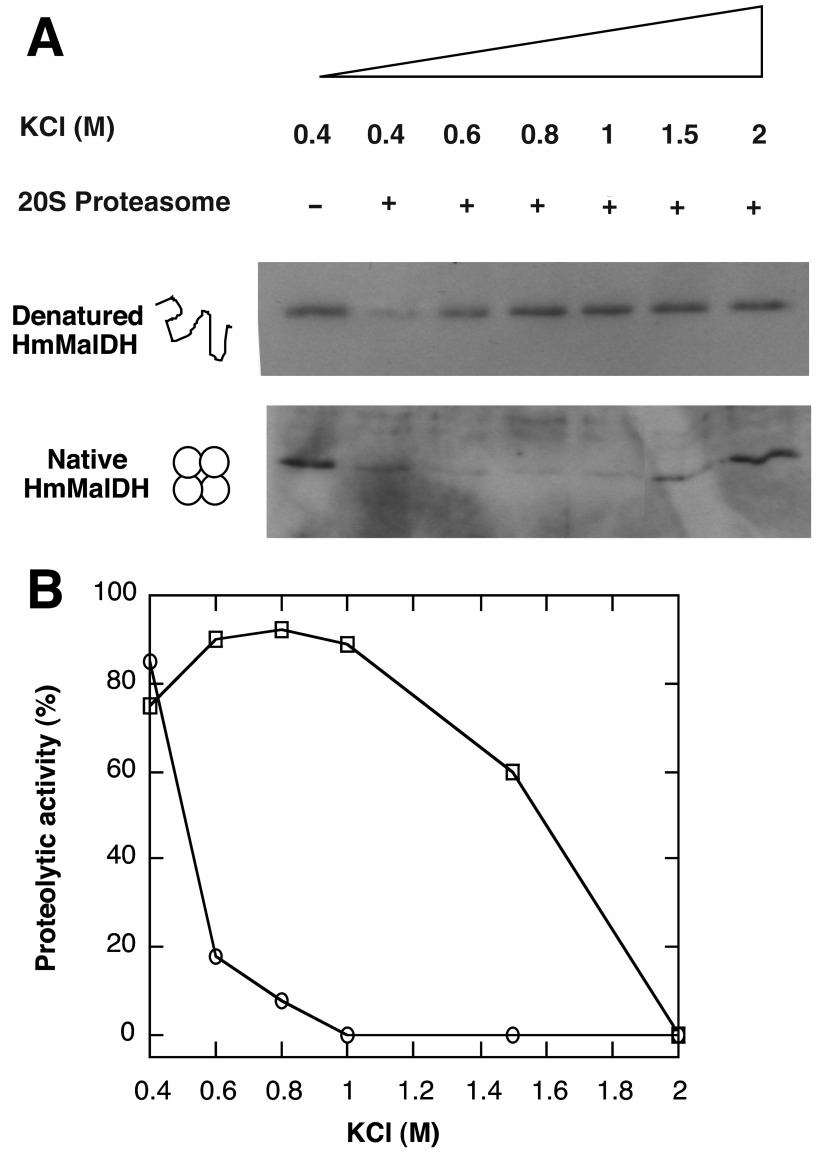

Figure 3. Halophilic proteasome processing of halophilic malate dehydrogenase (HmMalDH). The HmMalDH (native or denatured) was incubated at $40{ }^{\circ} \mathrm{C}$ with $\mathrm{Hm}$ proteasome at the indicated salt concentrations. (A) Protein breakdown was assessed by Western blot of the remaining HmMalDH. (B) Proteolytic activity with denatured $(O)$ or native $(\square) \mathrm{HmMalDH}$ as substrate as a function of $\mathrm{KCl}$ concentration. Western blot bands were scanned, and proteolytic activity was calculated as band intensity as a percent of control.

weight of the particle). The 3-D electron microscopy map clearly shows that the proteasome is made up of 14 monomers of each of two different protein subunits. The more spherical subunits are situated at both ends of the structure and the more elliptic subunits are located in the middle. Comparison between the electron microscopy map of the halophilic proteasome and the X-ray structure of the thermophilic proteasome from Thermoplasma acidophilum filtered to $2.0 \mathrm{~nm}$ shows that the two structures are similar in shape, as well as diameter and height $(11 \pm 0.6$ and $14 \pm 0.6 \mathrm{~nm}$, respectively). The halophilic proteasome, which functions in hypersaline conditions, and the thermophilic proteasome designed to function at temperatures close to $70^{\circ} \mathrm{C}$, have the same global structure, suggesting that no ultrastructural changes are necessary to adapt to different extreme environments. This also confirms that the proteasome is widespread and highly structurally conserved among archaea. a
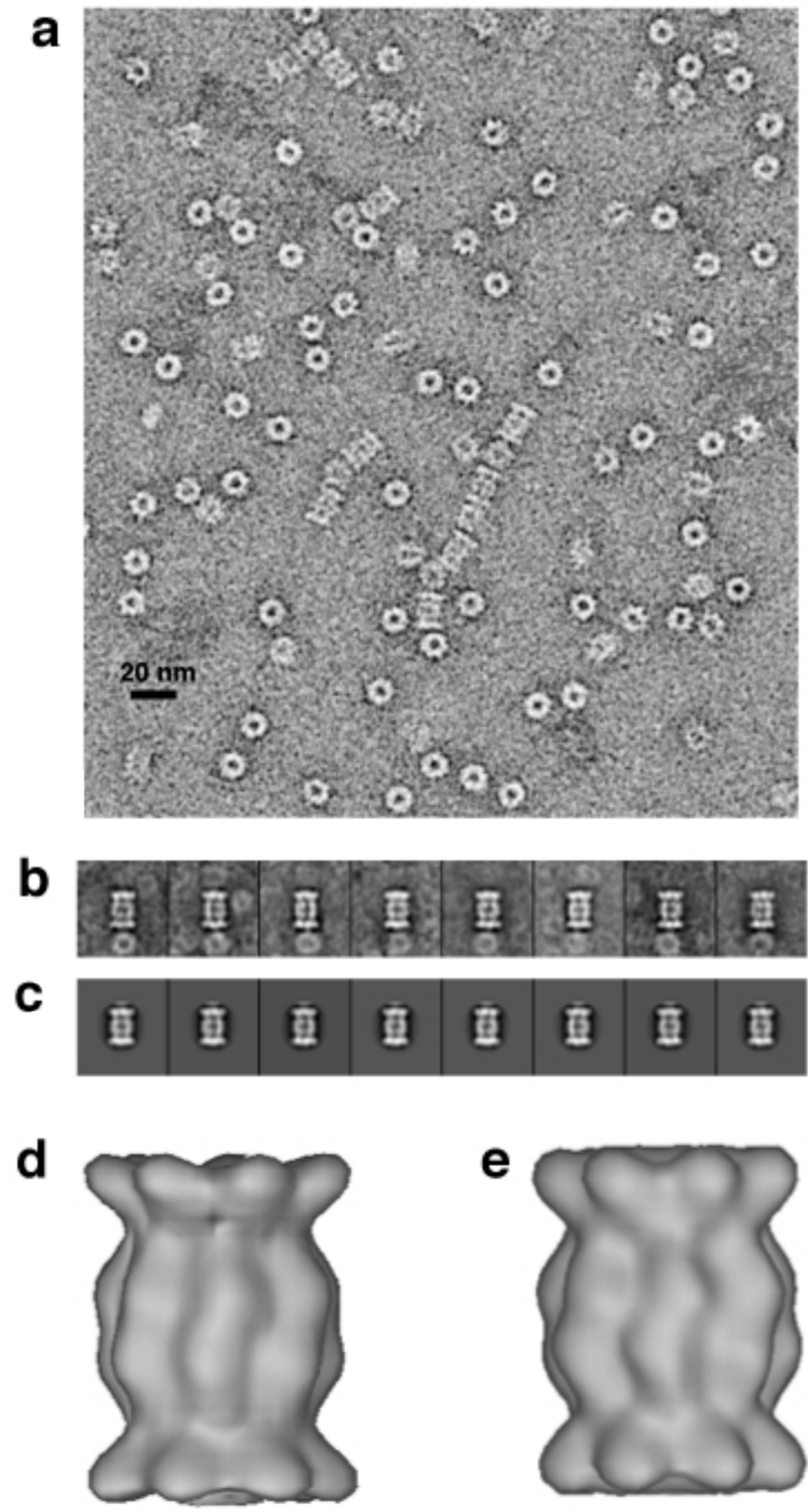

Figure 4. Negative staining and 3-D reconstruction of the halophilic proteasome. (a) Electron microscopy of a negatively stained sample of the halophilic proteasome. The image shows end and side views of the same object. The scale bar represents $20 \mathrm{~nm}$. (b) Class means of the proteasome. Every class is the mean of $10-15$ images. The side views are represented every $7^{\circ}$ in the asymmetric unit. The rings below the side views are present because each side view sticks to an end view (see a). (c) Reprojected views of the proteasome. The side views are represented every $7^{\circ}$ in the asymmetric unit. (d) 3-D reconstruction of the halophilic proteasome. (e) X-ray structure of the thermophilic proteasome filtered to $2.0 \mathrm{~nm}$.

\section{Discussion}

We have described the biochemical characterization of a proteasome from an extreme halophile, Haloarcula marismortui. An important contribution to the forces that stabilize a halophilic protein is the network of hydrated salt ions that cover the protein surface (Zaccai et al. 1989, Ebel et al. 1999). Consequently, halophilic proteins denature when the salt con- 
centration decreases. We found that the halophilic proteasome in H. marismortui, like that in $H$. volcanii, requires a high salt concentration (over $1 \mathrm{M} \mathrm{KCl}$ ) to remain stable, oligomeric and active over long periods; nevertheless, this typical halophilic feature is strikingly less pronounced than for other halophilic soluble enzymes like the tetrameric enzyme HmMalDH. Even at $0.5 \mathrm{M} \mathrm{KCl}$, the rate of inactivation of the proteasome is considerably slower than that of HmMalDH (not shown). The Hm proteasome is also stable at salt concentrations that are far below the growth optimum for $H$. marismortui, suggesting that the enzyme is stable even when cells are exposed to hyposaline stress. The high stability of the Hm proteasome under conditions that normally denature halophilic enzymes prompted us to test its proteolytic activity in salt shock conditions. We showed that, in vitro, the $20 \mathrm{~S} \mathrm{Hm}$ proteasome ensures efficient breakdown of a halophilic protein under hyposaline conditions (below $2 \mathrm{M} \mathrm{KCl}$ ). Taken together, these results suggest that the $\mathrm{Hm}$ proteasome functions to overcome the accumulation of low-salt damaged proteins in the cytoplasm and thus is part of a low-salt stress response system by which halophilic cells resist environmental changes. Other studies of archaea have also provided evidence that the proteasome functions to combat stress. For example, in thermophilic archaea, it was found that inhibition of proteasome activity reduces the ability of cells to tolerate heat shock (Maupin-Furlow et al. 1998, Ruepp et al. 1998).

We found that, when incubated with the Hm proteasome, fully denatured $\mathrm{HmMalDH}$ is degraded only in $0.4 \mathrm{M} \mathrm{KCl}$, whereas native $\mathrm{HmMalDH}$ is processed in destabilizing salt conditions ranging from 0.4 to $1.5 \mathrm{M} \mathrm{KCl}$. Electron microscopy of the Hm proteasome revealed that openings formed by the $\alpha$-subunits are too narrow to allow the entry of polypeptides with limited secondary structure to the central catalytic cavity. Therefore, as for other $20 \mathrm{~S}$ proteasomes, we would expect that in vitro protease activity is restricted to a few small proteins that were previously fully denaturated by heat, oxidative damage or disulfide bond reduction. On the contrary, the efficient breakdown of HmMalDH during its denaturation process suggests that partially folded proteins may constitute better substrates for the proteasome than fully denatured polypeptide chains. As observed for molecular chaperones, this could be associated with specific recognition of partially folded proteins (folding intermediates) through the transient exposure of hydrophobic patches (Badcoe et al. 1991, Martin et al. 1991, Ellis 2000), which could explain why HmMalDH is better degraded during denaturation. A similar recognition mechanism that involves increased surface hydrophobicity has also been proposed to explain why oxidized soluble proteins are efficiently degraded by the eukaryotic $20 \mathrm{~S}$ proteasome in a ubiquitin-independent manner (Pacifici et al. 1993).

Eukaryotic cells contain a ubiquitin-tagging system that targets the folded proteins to the proteasome via regulatory multi-subunit complexes such as the 19S (PA 700) complex, which activates protein breakdown by the $20 \mathrm{~S}$ proteasome (Ciechanover 1998). Ubiquitin or ubiquitin-processing genes have not been found in any of the completely sequenced genomes of archaea, but PAN, a homolog of the ATPases from the eukaryotic 19S regulatory complex (Rpts), has been reported in the archaeon Methanococcus jannaschii (Zwickl et al. 1999). This complex has been shown to activate the in vitro degradation of denatured casein and folded proteins (Zwickl et al. 1999, Benaroudj and Goldberg 2000). Two genes were identified as PAN homologs in the genome from Halobacterium sp., an extreme halophile ( $\mathrm{Ng}$ et al. 2000). The breakdown of abnormal cellular proteins is ATP dependent in vivo, suggesting that the 20S proteasome cannot function independently of PAN. Our data suggest that the contribution of such a complex is not a strict requirement for the functioning of the Hm proteasome in extreme salt shock conditions. However, it is likely that the crowded environment of the cell cytosol would influence the accessibility of substrate proteins to the active site and that, in these conditions, PAN may be required. Also, the 3-D structure of the Hm proteasome obtained from image reconstruction shows no structural difference compared to the 20S proteasome from T. acidophilum, which could account for its autonomous functioning of $\mathrm{Hm}$ proteasome. In conclusion, this in vitro study shows that the 20S halophilic proteasome is stable and functional in hyposaline conditions. It can efficiently cleave a halophilic protein during its denaturation by low salt concentration without the assistance of ATP-dependent regulatory complexes. The relevance of this finding for the in vivo functioning of the archaeal proteasome needs further exploration.

\section{Acknowledgments}

We thank Christine Ebel and Carolyn Teschke for critical review of the manuscript and Neil Ranson and Helen Saibil for providing the latest version of SPIDER procedures.

\section{References}

Akopian, T.N., A.F. Kisselev and A.L. Goldberg. 1997. Processive degradation of proteins and other catalytic properties of the proteasome from Thermoplasma acidophilum. J. Biol. Chem. 272: 1791-1798.

Badcoe, I.G., C.J. Smith, S. Wood, D.J. Halsall, J.J. Holbrook, P. Lund and A.R. Clarke. 1991. Binding of a chaperonin to the folding intermediates of lactate dehydrogenase. Biochemistry 30: 9195-9200.

Baumeister, W., J. Walz, F. Zuhl and E. Seemuller. 1998. The proteasome: paradigm of a self-compartmentalizing protease. Cell 92: 367-380.

Benaroudj, N. and A.L. Goldberg. 2000. PAN, the proteasome-activating nucleotidase from archaebacteria, is a protein-unfolding molecular chaperone. Nat. Cell Biol. 2:833-839.

Bonnete, F., D. Madern and G. Zaccai. 1994. Stability against denaturation mechanisms in halophilic malate dehydrogenase "adapt" to solvent conditions. J. Mol. Biol. 244:436-447.

Bradford, M.M. 1976. A rapid and sensitive method for the quantitation of microgram quantities of protein utilizing the principle of protein-dye binding. Anal. Biochem. 72:248-254. 
Cendrin, F., J. Chroboczek, G. Zaccai, H. Eisenberg and M. Mevarech. 1993. Cloning, sequencing, and expression in Escherichia coli of the gene coding for malate dehydrogenase of the extremely halophilic archaebacterium Haloarcula marismortui. Biochemistry 32:4308-4313.

Ciechanover, A. 1998. The ubiquitin-proteasome pathway: on protein death and cell life. EMBO J. 17:7151-7160.

Coux, O., K. Tanaka and A.L. Goldberg. 1996. Structure and functions of the 20S and 26S proteasomes. Annu. Rev. Biochem. 65: 801-847.

Crowther, R.A., R. Henderson and J.M. Smith. 1996. MRC image processing programs. J. Struct. Biol. 116:9-16.

Dahlmann, B., F. Kopp, L. Kuehn, B. Niedel, G. Pfeifer, R. Hegerl and W. Baumeister. 1989. The multicatalytic proteinase (prosome) is ubiquitous from eukaryotes to archaebacteria. FEBS Lett. 251: $125-131$

Dym, O., M. Mevarech and J.L. Sussman. 1995. Structural features that stabilize halophilic malate dehydrogenase from an archaebacterium. Science 267:1344-1346.

Ebel, C., P. Faou, B. Kernel and G. Zaccai. 1999. Relative role of anions and cations in the stabilization of halophilic malate dehydrogenase. Biochemistry 38:9039-9047.

Eisenberg, H., M. Mevarech and G. Zaccai. 1992. Biochemical, structural, and molecular genetic aspects of halophilism. Adv. Protein Chem. 43:1-62.

Ellis, R.J. and F.U. Hartl. 1999. Principles of protein folding in the cellular environment. Curr. Opin. Struct. Biol. 9:102-110.

Ellis, R.J. 2000. Chaperone substrates inside the cell. Trends Biochem. Sci. 25:210-212.

Frolow, F., M. Harel, J.L. Sussman, M. Mevarech and M. Shoham. 1996. Insights into protein adaptation to a saturated salt environment from the crystal structure of a halophilic $2 \mathrm{Fe}-2 \mathrm{~S}$ ferredoxin. Nat. Struct. Biol. 3:452-458.

Ginzburg, M., L. Sachs and B.Z. Ginzburg. 1970. Ion metabolism in a Halobacterium. I. Influence of age of culture on intracellular concentrations. J. Gen. Physiol. 55:187-207.

Glickman, M.H., D.M. Rubin, O. Coux, I. Wefes, G. Pfeifer, Z. Cjeka, W. Baumeister, V.A. Fried and D. Finley. 1998. A subcomplex of the proteasome regulatory particle required for ubiquitin-conjugate degradation and related to the COP9-signalosome and eIF3. Cell 94:615-623.

Hershko, A. and A. Ciechanover. 1998. The ubiquitin system. Annu. Rev. Biochem. 67:425-479.

Horwich, A.L., E.U. Weber-Ban and D. Finley. 1999. Chaperone rings in protein folding and degradation. Proc. Natl. Acad. Sci. 96: 11,033-11,040.

Kisselev, A.F., T.N. Akopian, K.M. Woo and A.L. Goldberg. 1999. The sizes of peptides generated from protein by mammalian 26 and $20 \mathrm{~S}$ proteasomes. Implications for understanding the degradative mechanism and antigen presentation. J. Biol. Chem. 274: 3363-3371.

Laemmli, U.K. 1970. Cleavage of structural proteins during the assembly of the head of bacteriophage T4. Nature 227:680-685.

Lowe, J., D. Stock, B. Jap, P. Zwickl, W. Baumeister and R. Huber. 1995. Crystal structure of the $20 \mathrm{~S}$ proteasome from the archaeon T. acidophilum at $3.4 \AA$ resolution. Science 268:533-539.

Lupas, A., J.M. Flanagan, T. Tamura and W. Baumeister. 1997. Self-compartmentalizing proteases. Trends Biochem. Sci. 22: 399-404.

Madern, D., C. Pfister and G. Zaccai. 1995. Mutation at a single acidic amino acid enhances the halophilic behaviour of malate dehydrogenase from Haloarcula marismortui in physiological salts. Eur. J. Biochem. 230:1088-1095.
Madern, D., C. Ebel and G. Zaccai. 2000. Halophilic adaptation of enzymes. Extremophiles 4:91-98.

Martin, J., T. Langer, R. Boteva, A. Schramel, A.L. Horwich and F.U. Hartl. 1991. Chaperonin-mediated protein folding at the surface of GroEL through a 'molten globule'-like intermediate. Nature 352: $36-42$.

Maupin-Furlow, J.A., H.C. Aldrich and J.G. Ferry. 1998. Biochemical characterization of the $20 \mathrm{~S}$ proteasome from the methanoarchaeon Methanosarcina thermophila. J. Bacteriol. 180: 1480-1487.

Maupin-Furlow, J.A., H.L. Wilson, S.J. Kaczowka and M.S. Ou. 2000. Proteasomes in the Archaea: from structure to function. Front. Biosci. 5:d837-865.

Mevarech, M., H. Eisenberg and E. Neumann. 1977. Malate dehydrogenase isolated from extremely halophilic bacteria of the Dead Sea. I. Purification and molecular characterization. Biochemistry $16: 3781-3785$.

Mojica, F.J., E. Cisneros, C. Ferrer, F. Rodriguez-Valera and G. Juez. 1997. Osmotically induced response in representatives of halophilic prokaryotes:the bacterium Halomonas elongata and the archaeon Haloferax volcanii. J. Bacteriol. 179:5471-5481.

Mullakhanbhai, M.F and H. Larsen. 1975. Halobacterium volcanii spec. nov., a Dead Sea Halobacterium with a moderate salt requirement. Arch. Microbiol. 104:207-214.

Ng, W.V., S.P. Kennedy, G.G Mahairas, et al. 2000. From the cover: genome sequence of Halobacterium species NRC-1. Proc. Natl. Acad. Sci. 97:12,176-12,181.

Pacifici, R.E., Y. Kono and K.J. Davies. 1993. Hydrophobicity as the signal for selective degradation of hydroxyl radical-modified hemoglobin by the multicatalytic proteinase complex, proteasome. J. Biol. Chem. 268:15,405-15,411.

Patel, S. and M. Latterich. 1998. The AAA team: related ATPases with diverse functions. Trends Cell Biol. 8:65-71.

Pieper, U., G. Kapadia, M. Mevarech and O. Herzberg. 1998. Structural features of halophilicity derived from the crystal structure of dihydrofolate reductase from the Dead Sea halophilic archaeon, Haloferax volcanii. Structure 6:75-88.

Pundak, S., H. Aloni and H. Eisenberg. 1981. Structure and activity of malate dehydrogenase from the extreme halophilic bacteria of the Dead Sea. II. Inactivation, dissociation and unfolding at $\mathrm{NaCl}$ concentrations below $2 \mathrm{M}$. Salt, salt concentration and temperature dependence of enzyme stability. Eur. J. Biochem. 118:471-477.

Richard, S.B., D. Madern, E. Garcin and G. Zaccai. 2000. Halophilic adaptation: novel solvent protein interactions observed in the 2.9 and 2.6 A resolution structures of the wild type and a mutant of malate dehydrogenase from Haloarcula marismortui. Biochemistry 39:992-1000.

Rivett, A.J., P.J. Savory and H. Djaballah. 1994. Multicatalytic endopeptidase complex: proteasome. Methods Enzymol. 244:331-350.

Roseman, A.M., S. Chen, H. White, K. Braig and H.R. Saibil. 1996. The chaperonin ATPase cycle: mechanism of allosteric switching and movements of substrate-binding domains in GroEL. Cell 87: 241-251.

Ruepp, A., C. Eckerskorn, M. Bogyo and W. Baumeister. 1998. Proteasome function is dispensable under normal but not under heat shock conditions in Thermoplasma acidophilum. FEBS Lett. 425:87-90.

Russell, S.J., U.G. Sathyanarayana and S.A. Johnston. 1996. Isolation and characterization of SUG2. A novel ATPase family component of the yeast 26 S proteasome. J. Biol. Chem. 271:32,810-32,817.

Schmidt, M., A.N. Lupas and D. Finley. 1999. Structure and mechanism of ATP-dependent proteases. Curr. Opin. Chem. Biol. 3: 584-591. 
Seemuller, E., A. Lupas, D. Stock, J. Lowe, R. Huber and W. Baumeister. 1995. Proteasome from Thermoplasma acidophilum: a threonine protease. Science 268:579-582.

Seemuller, E., A. Lupas and W. Baumeister. 1996. Autocatalytic processing of the 20S proteasome. Nature 382:468-471.

Sherman, M.Y. and A.L. Goldberg. 2001. Cellular defense against unfolded proteins: a cell biologist thinks about neurodegenerative diseases. Neuron 29:15-32.

Timasheff, S.N. 1993. The control of protein stability and association by weak interactions with water: how do solvents affect these processes? Annu. Rev. Biophys. Biomol. Struct. 22:67-97.

Wickner, S., M.R. Maurizi and S. Gottesman. 1999. Posttranslational quality control: folding, refolding, and degrading proteins. Science 286:1888-1893.

Wilson, H.L., H.C. Aldrich and J. Maupin-Furlow. 1999. Halophilic $20 \mathrm{~S}$ proteasomes of the archaeon Haloferax volcanii: purification, characterization, and gene sequence analysis. J. Bacteriol. 181: $5814-5824$.
Wilson, H.L., M.S. Ou, H.C. Aldrich and J. Maupin-Furlow. 2000 Biochemical and physical properties of the Methanococcus jannaschii 20S proteasome and PAN, a homolog of the ATPase (Rpt) subunits of the eucaryal 26S proteasome. J. Bacteriol. 182: 1680-1692.

Zaccai, G., G.J. Bunick and H. Eisenberg. 1986. Denaturation of a halophilic enzyme monitored by small-angle neutron scattering. J. Mol. Biol. 192:155-157.

Zaccai, G., F. Cendrin, Y. Haik, N. Borochov and H. Eisenberg. 1989. Stabilization of halophilic malate dehydrogenase. J. Mol. Biol. 208:491-500.

Zwickl, P., A. Grziwa, G. Puhler, B. Dahlmann, F. Lottspeich and W. Baumeister. 1992. Primary structure of the Thermoplasma proteasome and its implications for the structure, function, and evolution of the multicatalytic proteinase. Biochemistry 31: 964-972.

Zwickl, P., D. Ng, K.M. Woo, H.P. Klenk and A.L. Goldberg. 1999. An archaebacterial ATPase, homologous to ATPases in the eukaryotic $26 \mathrm{~S}$ proteasome, activates protein breakdown by $20 \mathrm{~S}$ proteasomes. J. Biol. Chem. 274:26,008-26,014. 

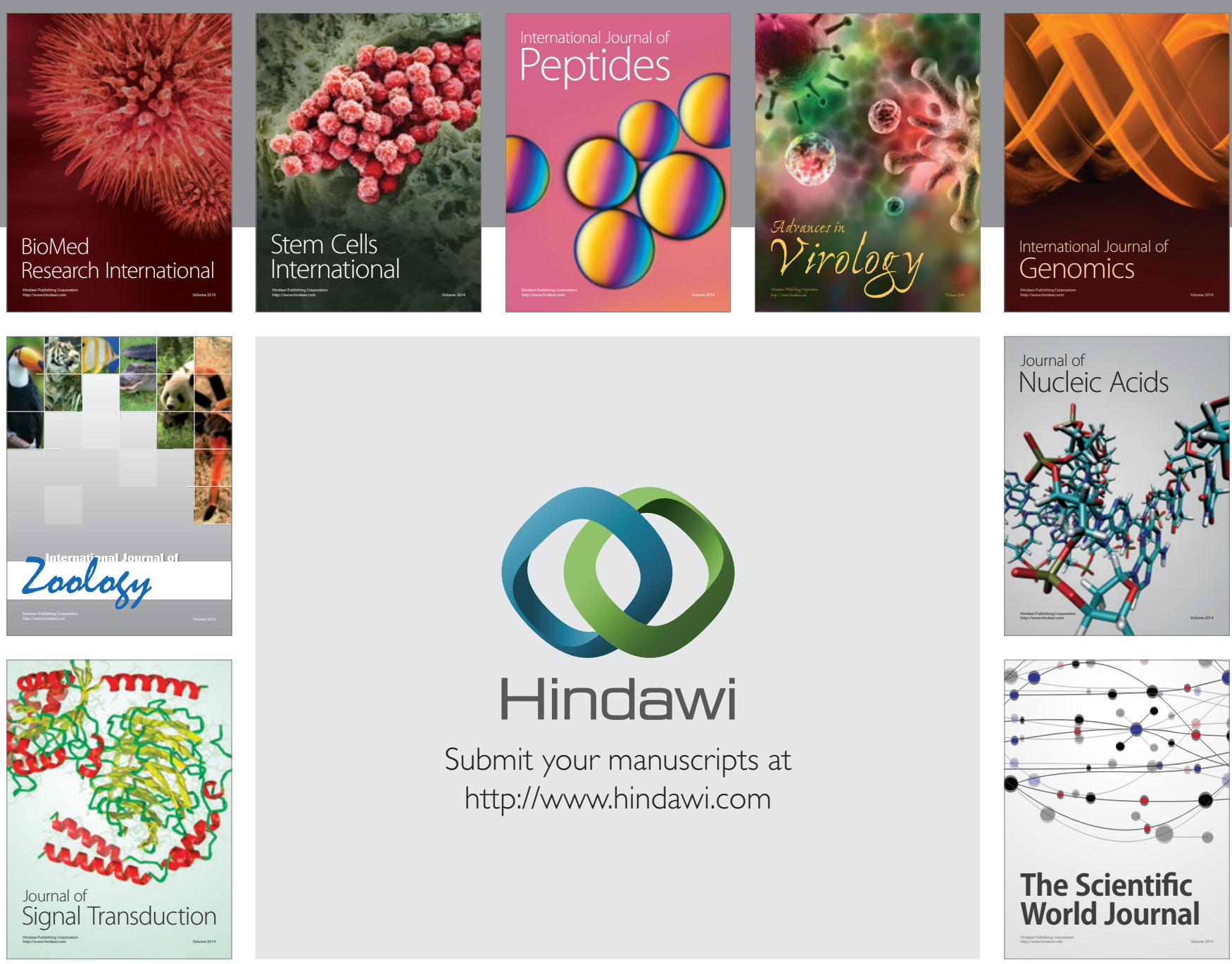

Submit your manuscripts at

http://www.hindawi.com
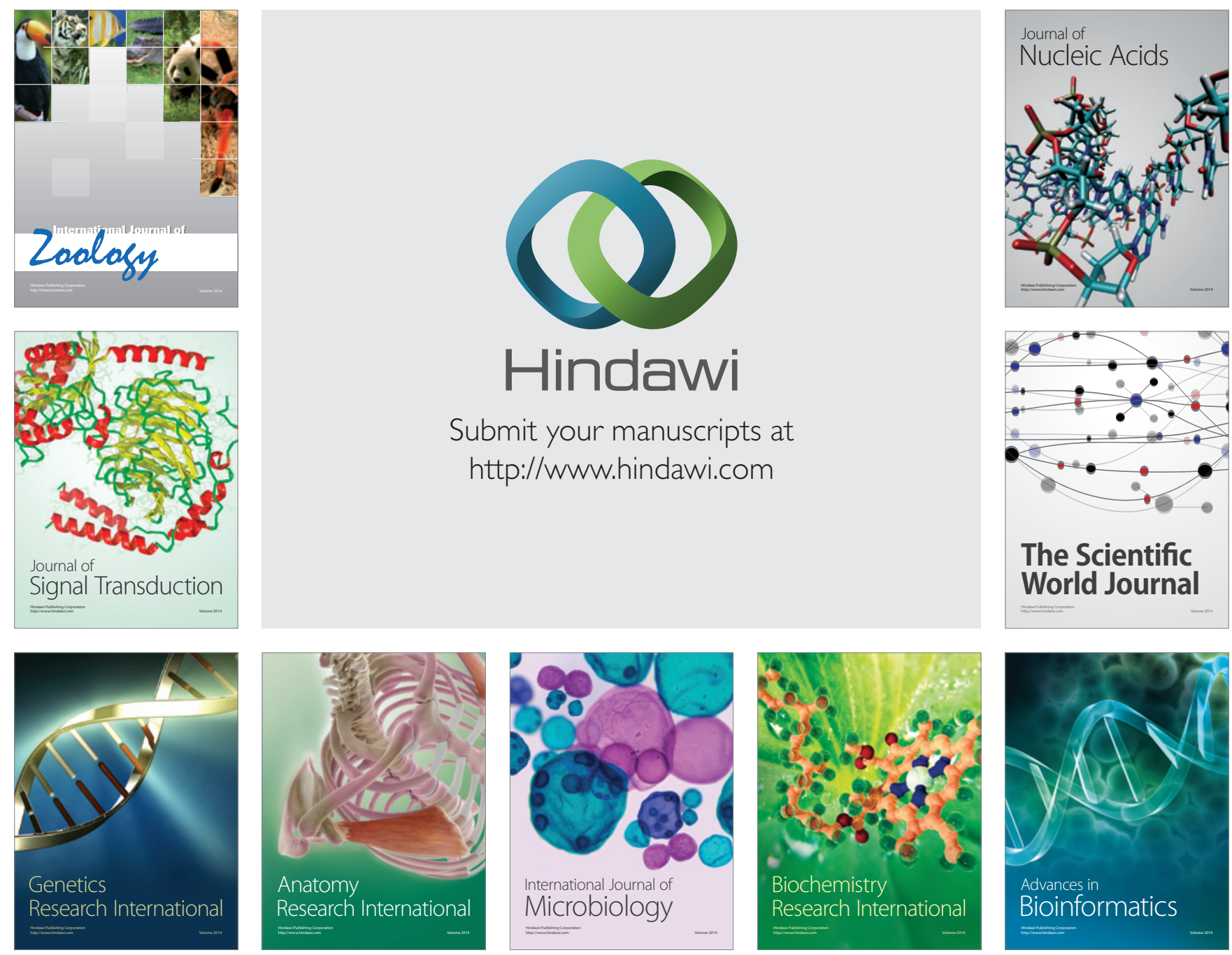

The Scientific World Journal
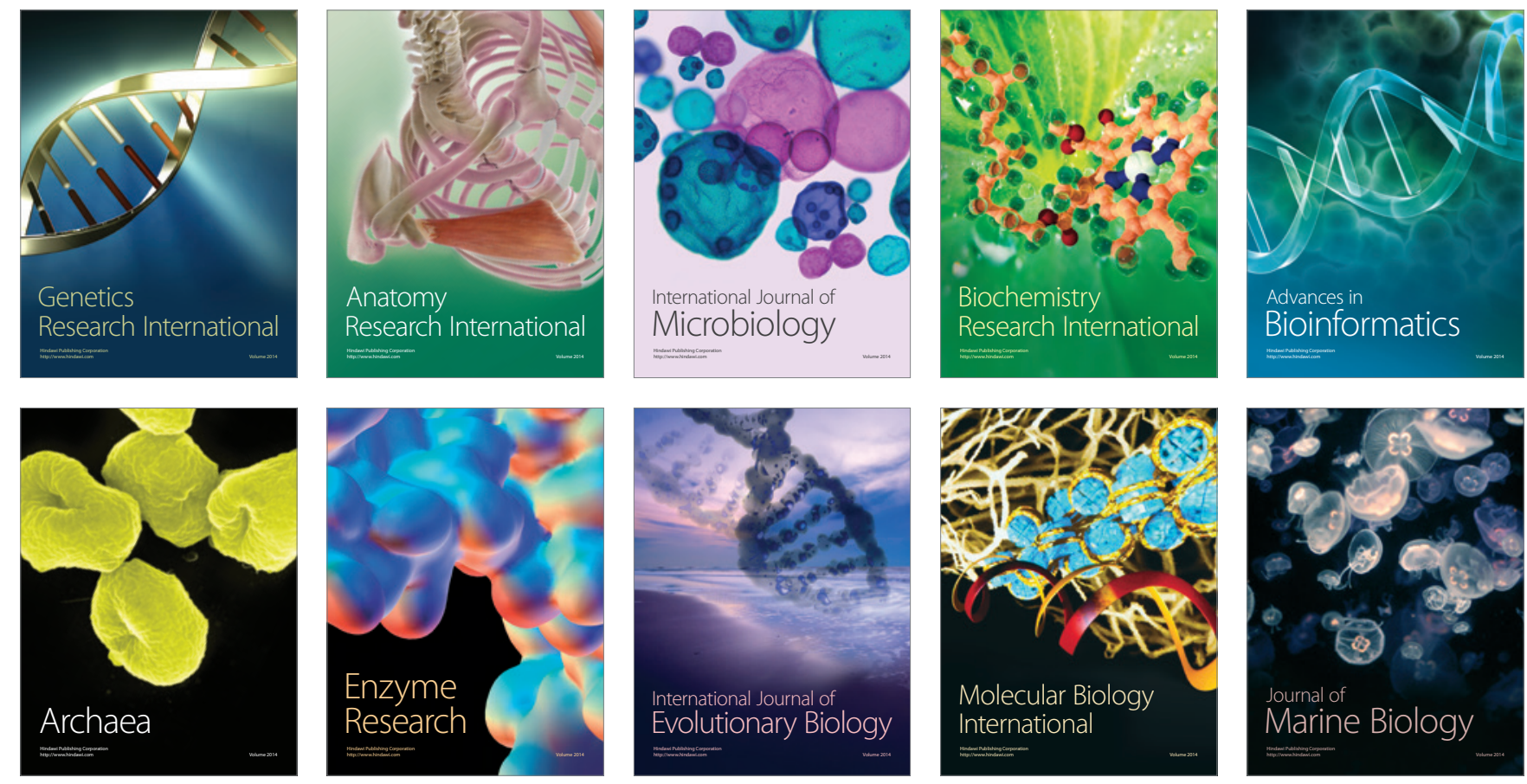